\title{
ANALISIS MANAJEMEN IMPRESI PENGGEMAR K-POP DALAM MEMANIPULASI DIRI DI SOCIAL NETWORKING SITE (SNS)
}

\author{
Annisa Fitriana Lestari, Eriyanto
}

Universitas Indonesia

\begin{abstract}
K-Pop fans use a variety of media to connect with their idols and fandoms, one of them with SNS. But they still worry that their self-image will be damaged in the perspective of others who are neutral or don't like K-Pop. Instagram as one type of SNS, provides opportunities for individuals to create more than one user account. Instagram becomes a way out for K-Pop fans to manipulate themselves with real accounts (rinsta) and fake accounts (finsta). This research was conducted using qualitative on four teenagers who are K-Pop fans and have real and fake Instagram accounts. Data collected by interview and observation. The results showed that K-Pop fans used risnta as the front stage and finsta as their background to express their true selves.
\end{abstract}

\section{Keywords}

Penggemar, Social Networking Site, Manajemen Impresi, Online Disinhibition Effect.

Correspondence Contact afelonew@gmail.com

\section{PENDAHULUAN}

Dimulai pada tahun 1990-an, terkenal istilah hallyu atau gelombang budaya Korea (Korean Wave) yaitu fenomena yang menggambarkan popularitas hiburan dan budaya Korea ke seluruh Asia dan belahan dunia lainnya (Korea.net, 2019). Salah satu bentuk dari hallyu adalah musik asal Korea yang dikenal dengan sebutan K-Pop. K-Pop (Korean pop music) adalah genre musik yang berkembang pada abad ke-21 dengan mencangkup R\&B; dance dan balad pop; hip-hop; techno; rock; dan sebagainya (Korea.net, 2019). Berawal dari hanya sebagai sebuah genre musik, K-Pop berubah menjadi bentuk sub budaya (subculture) di antara anak muda (remaja dan dewasa muda) pada wilayah Asia Tenggara dan Timur. Saat ini selain masyarakat Asia, K-Pop telah merambah dan dinikmati hingga benua Amerika dan Eropa. K-Pop memiliki suatu karakteristik yang berbeda dari genre musik lainnya, yaitu adanya kehadiran boy band dan girl band yang melakukan tarian sambal bernyanyi.

Masuknya hallyu ke Indonesia sendiri tidak diawali dengan pengenalan K-Pop, melainkan masyarakat lebih dulu terpikat dengan drama-drama dari Korea. Lewat penayangan di TV swasta pada awal tahun 2000an, drama Korea mulai masuk ke Indonesia (Hidayati, 2017). Melalui drama-drama Korea, K-Pop hadir sebagai soundtrack di dalamnya. Lagu-lagu yang terdengar selama episode drama-drama Korea ini membuat penonton penasaran, hingga mencari tahu lebih dalam dan berujung dengan mendengarkan musik-musik K-Pop tersebut. Namun bersamaan dengan hadirnya K-Pop, fenomena lain yang mengikuti adalah istilah fan (penggemar), idol (idola), dan fandom.

Penggemar (fan) istilah bagi individu yang memiliki obsesi terhadap objek, misalnya seperti artis (Dean, 2017). Survei yang dilakukan Kumparan (Nurani, 2017) menunjukkan bahwa dari 100 orang penggemar K-Pop di Indonesia, 57\% masih termasuk dalam kelompok usia $12-20$ tahun (remaja dan dewasa awal). Sisanya sebesar $42 \%$ adalah penggemar dengan rentang usia 21-30 tahun dan satu persen adalah 30 tahun keatas. Idola (idol) merupakan sebutan bagi 
individu atau kelompok yang memiliki ketenaran dan popularitas dan ketenaran yang membuatnya dikenali oleh masyarakat umum (Ang dan Chan, 2016). Fandom adalah dunia bagi kumpulan individu-individu yang menyatakan dirinya sebagai penggemar pada suatu hiburan atau artis (Hagen, 2010). Melalui fandom, penggemar secara lebih aktif terlibat dalam kegiatan di dalamnya dengan melakukan interaksi antaranggota kelompok baik secara online maupun offline, atau disebut dengan partisipatif fandom (Jefkins, 1992 dalam Fleming, 2007).

Penggemar merupakan konsumen dan produsen dari konten media Jefkins, 1992 dalam Fleming, 2007). Sebagai konsumen, penggemar secara aktif membeli album K-Pop idolanya; membeli dan menonton konser; mengunduh segala konten yang berkaitan dengan idolanya, seperti music vieo (MV), penampilan idola, lagu, variety show; mencari informasi terkait idola diberbagai forum atau medial; dan membeli merchandise (Tartila, 2013). Sebagai produsen, penggemar K-Pop melakukan cover video atau cosplay seperti idolanya; menjadi fansite yang menghasilkan foto-foto kegiatan idolanya dan kemudia dijual ke penggemar lainnya; dan menjual merchandise. Selain penggemar (fan), terdapat masyarakat umum yang dapat disebut non-fan. Masyarakat umum (non-fan) memandang diri mereka normal dan melihat obsesi yang ada pada diri penggemar terhadap idolanya adalah sesuatu hal yang negatif (Casey, dalam Rayner, Wall, dan Kruger, 2004). Pandangan atau stereotip negatif ini membuat tidak semua penggemar K-Pop berani menunjukkan aktivitasnya.

Seperti yang dijelaskan sebelumnya aktivitas penggemar dapat dilakukan secara online. Baik penggemar (fan) dan masyarakat umum (non-fan) merupakan konsumen dari produk digital, yaitu social networking site. Social Networking Site (SNS) merupakan suatu lingkungan dalam bentuk cyber yang memberikan kesempatan bagi individu untuk membuat profilnya, berbagi teks, gambar, dan foto, serta terhubung dalam suatu keanggotaan suatu situs atau aplikasi dan grup yang disediakan di internet (Lin dan Lu, 2011).

Salah satu bentuk SNS yang banyak digunakan adalah Instagram. Di Indonesia, hingga November 2019 pengguna aktif Instagram telah mencapai 61.610 .000 atau sama dengan $22,6 \%$ dari jumlah penduduk di Indonesia (NepoleonCat, dalam Pertiwi, 2019). Jumlah kelompok pengguna terbesar terletak pada rentang usia 18 hingga 24 tahun dengan total $37,3 \%$ atau 37 juta pengguna.

Tahun 2017, Instagram memperbolehkan penggunanya membuat atau beralih dengan banyak akun (Orlando, 2018). Kebijkan ini diikuti oleh Twitter pada tahun 2019, dimana hanya dapat dilakukan pada versi web dan Twitter Lite (Hutchinson, 2019). Berbeda dengan Instagram dan Twitter, Facebook melarang penggunanya untuk memiliki lebih dari satu akun (Orlando, 2018). Kehadiran kebijakan ini memunculkan tren rinsta dan finsta di kalangan remaja pengguna Instagram (Orlando, 2018). Rinsta adalah istilah yang digunakan untuk sebutan akun Instagram asli, sementara finsta adalah sebutan untuk akun Instagram palsu. Dalam membuat finsta, remaja pada umumnya tidak menggunakan nama asli mereka, melainkan nama palsu atau entitas seperti karakter favoritnya. Para remaja beranggapan bahwa kehadiran finsta dengan nama palsu tidak mudah dilacak keterkaitannya dengan mereka.

Kehadiran rinsta dan finsta ini dapat menjadi media untuk remaja melakukan manipulasi diri. Manipulasi diri (self manipulation) berkaitan dengan konsep manajemen impresi yang dikembangkan oleh Ervin Goffman. Menurut Goffman saat melakukan interaksi sosial, individu (aktor) dramaturgis memunculkan 'pengertian diri' untuk memunculkan kesan dan dapat diterima oleh audiens (Hindarto, 2017). Individu melakukan manipulasi di SNS guna dapat diterima oleh individu lain dengan menunjukkan sisi normal mereka melalui rinsta yang berfungsi sebagai latar depan atau front region. Sementara individu juga menyembunyikan sisi negatif atau obsesinya di finsta yang berfungsi sebagai latar belakang atau backstage. 
Finsta sebagai latar belakang atau backstage digambarkan Suler (2004, dalam (Hindarto, 2017) sebagai bentuk dari online disinhibition effect. Online disinhibition effect adalah kondisi dimana individu merasa tidak terkekang, merasa lebih bebas, dan mengekspresikan dirinya di media online (Suler, 2004).

Hal ini memungkinkan penggemar K-Pop melakukan manajemen impresi untuk memanipulasi dirinya dengan memanfaatkan kelebihan dari SNS. Penggemar K-Pop yang memperhatikan kesan dan menutupi stereotip negatif dengan membuat rinsta untuk menunjukkan kesan normal kepada pengikutnya atau pengguna SNS secara umum, atau bentuk dari latar depannya (front region). Di lain sisi penggemar K-Pop membuat finsta untuk dapat bebas melakukan obsesinya dan alat untuk melakukan partisipasi fandom tanpa memiliki kekhwatiran menimbulkan kesan negatif pada diri aslinya, atau dapat disebut sebagai latar belakang (backsatge).

Studi tentang finsta telah diteliti oleh Dewar, dkk. (2019) yang juga didasari pada hasil penemuan Goffman. Penelitian ini menunjukkan bahwa kelompok remaja dan dewasa muda membentuk finsta untuk membedakan pengikut guna menghindari tumpang tindih dari konten dan menjaga identitas presentasi dirinya. Studi lain tetang manajemen impresi penggemar K-Pop dilakukan oleh Kenzy dan Sugandi (2018) yang menunjukkan bahwa pada latar depan penggemar K-Pop dapat merasakan diri mereka hampir serupa dengan dirinya dan menjadi pribadi biasa di latar belakangnya. Studi online dinishibition effect pada penggemar dan fandom diteliti oleh Rick, dkk. (2019) dimana perilaku yang muncul sering berkaitan dengan cara komunikasi yang toxic (negatif). Dari uraian diatas, tujuan dari tulisan ini adalah untuk:

a. Menganalisis latar depan dan latar belakang penggemar K-Pop yang memanfaatkan lebih dari satu akun SNS.

b. Menganalisis cara penggemar K-Pop melakukan manajemen impresi pada setiap akun SNS yang dimilikinya.

c. Menganalisis bentuk online disinhibition effect yang muncul pada penggemar K-Pop.

d. Menganalisis faktor online disinhibition effect yang paling mendominasi diri penggemar K-Pop.

\section{KAJIAN TEORITIK}

Penggemar (Fan)

Fan (penggemar) berasal dari kata fanatik yang memiliki arti terobsesi, gila, dan hilang kendali akan sesuatu hal yang disukai (Laughey, 2010). Jenkins (dalam Laughey, 2010) menyatakan bahwa penggemar adalah sesuatu yang bernilai, kreatif, dan sekaligus produktif, di mana mereka memanfaatkan media tidak hanya untuk berinteraksi dengan idolanya tetapi juga menjadi faktor bagaimana idola mereka seharusnya ditampilkan.

Menurut Samra dan Wos (2015) penggemar terbagi menjadi tiga kelompok, yaitu:

a. Temporary fan merupakan individu yang tertarik pada suatu objek tetapi dibatasi oleh waktu.

b. Devoted fan adalah individu yang setia pada objek yang digemarinya (bagian identifikasi diri) tetapi belum menjadi bagian terpenting dalam kehidupannya.

c. Fanatical fan yaitu individu yang menunjukkan kesetiaan kepada objek kegemarannya, dengan komitmen, pengabdian, dan keterikatan emosianal. 


\section{Fandom}

Fandom adalah sebutan bagi komunitas budaya yang mempunyai model penerimaan yang sama terhadap suatu tradisi yang merupakan produk estetika; kategori dan praktik kritis; serta seperangkat dan harapan sosial (Jefkins, 1992 dalam Dean, 2017).

Partisipasi fandom (fandom participatory) merupakan kondisi penggemar yang secara terus menerus melakukan tindakan aktif pada objek kegemarannya, serta memberikan dampak besar bagi media massa dan masyarakat (Jefkins, 1992, dalam (Fleming, 2007). Penggemar terlibat dalam partisipatif fandom karena mereka menjadikan idolanya sebagai model, atau tertarik pada idolanya melalui proses identifikasi dengan orang lain yang memiliki kegemaran yang sama (Fleming, 2007).

\section{Social Networking Site (SNS)}

Social Networking Site (SNS) adalah salah satu berntuk web yang memberikan pelayanan bagi individu untuk membentuk profil (publik atau semi-publik) yang terikat dalam sistem; terhubung dengan individu lain; dan pengguna dapat menemukan atau melintasi daftar hubungan pengguna lain yang ada dalam sistem (Liu dan Ying, 2012).

a. Profil (profile)

Profil merupakan tampilan pengguna dalam sistem untuk dilihat pengguna lain yang berisikan tentang usia, lokasi, minat, kolom deskripsi diri dan foto yang diunggah.

b. Pertemanan (friend)

Setelah tergabung dalam SNS, pengguna diminta untuk mengelompokan jenis hubungan dengan pengguna lain.

c. Komentar (comment)

Suatu mekanisme di mana pengguna dapat meninggalkan pesan di profil teman mereka dan fitur pesan pribadi seperti penggunaan webmail.

\section{Instagram}

Instagram merupakan aplikasi seluler untuk mengabadikan dan berbagi momen melalui serangkaian foto atau video yang difilter (manipulasi) (Hu, Manikonda, dan Kambhampati, 2014). Instagram pertama kali diluncurkan pada tahun 2010 sudah dapat menarik pengguna aktif sebanya 150 juta pengguna. Instagram hadir dengan memiliki beberapa fitur (Mahendra, 2017), yaitu:

a. Kamera merupakan fitur untuk menggunggah foto secara langsung dan juga mengambilnya dari galeri.

b. Editor yaitu fitur yang dapat digunakan pengguna untuk memanipulasi foto atau video yang ingin diunggah.

c. Tag dan hashtag adalah fitur yang memiliki fungsi untuk menandai teman atau mengelompokkan foto dalam satu label.

d. Caption merupakan deskripsi dari momen dimana pengguna mengisinya dengan beberapa kata sebelum diunggah.

e. Integrasi ke SNS lainnya dapat dilakukan melalui Instagram.

f. Instastory adalah fitur dimana unggahan hanya akan bertahan selama 1(satu) hari dengan durasi maksimal 10 detik. 
g. Explore menampilkan konten dari pengguna lainnya baik mereka saling mengikuti atau tidak.

\section{Manajemen Impresi (Impression Management)}

Konsep manajemen impresi merupakan bagian dari teori dramaturgi yang dikembangakn Ervin Goffman pada tahun 1959. Dramaturgi dianggap sebagai panggung sandiwara, dimana individu memiliki karakter latar depan (front region) dan latar belakang (back region) (Alim, 2014). Latar depan (front region) adalah karakter seseorang di ruang publik untuk berinteraksi secara tatap muka dengan individu lain (interpersonal) atau khalayak luas. Sementara latar belakang (back region) merupakan karakter yang disembunyikan seseorang dari pandangan publik.

Menurut Goffman (1959, dalam Mclane, 2012) individu menampilkan gambaran diri (impresi) sesuai harapan orang lain di latar depan agar dapat diakui dan diterima selama mereka berinteraksi. Terdapat lima strategi yang digunakan individu untuk membentuk presentasi dirinya sebagai cara memanajemen impresi kepada orang lain (Jones dan Pittman, 1982, dalam Mclane, 2012), yaitu:

a. Ingratiation

Bentuk strategi untuk membentuk kesan dengan menonjolkan salah satu karakteristik diri yang disukai oleh semua orang.

b. Intimidation

Strategi yang memanfaatkan kekuatan dengan dua cara, yaitu ancaman (threats) dan amarah (anger).

c. Self-promotion

Membentuk kesan dengan menampilkan kompetensi dalam diri kepada orang lain dengan menunjukkan kemampuan secara langsung atau menunjukkan hasil kerja yang telah dilakukan.

d. Exemplification

Menunjukkan kepemilikan moral yang tinggi dalam diri ini untuk menciptakan kesan dengan menunjukkan dedikasi, pengorbanan, komitmen, dan menjadi panutan orang lain.

e. Supplication

Mencari simpati pada orang lain dengan menunjukkan karakter diri yang lemah, rendah diri, dan sederhana sebagai strategi membentuk impresi.

\section{Online Disinhibition Effect}

Online disinhibition effect adalah kaburnya hambatan atau aturan sosial ketika berinteraksi di internet yang berbeda dengan pertemuan secara face to face dengan orang lain (Suler, 2004). Saat di dunia nyata (offline) individu banyak mengalami hambatan psikologis dimana tertahannya emosi dan tertutupnya kebutuhan (undisclosed needs) ketika berhadapan dengan harapan orang lain, sehingga memunculkan perilaku khusus di dunia maya (Gackenbach, 2007 dalam Satriawan, Hardjono, dan Karyanta, 2016).

Namun, pada praktiknya terdapat dua bentuk dari online disinhibition effect menurut Suler (2004) yaitu toxic disinhibition dan benign disinhibition. Benign disinhibition adalah kondisi seseorang lebih terbuka dengan perasaan mereka, mampu mengungkapkan emosi, ketakutan, dan harapan (Suler, 2004). Keterbukaan yang menunjukkan kebaikan, kemurahan, dan 
terkadang tindakan membantu orang lain. Sementara toxic disinhibition adalah kondisi di mana seseorang lebih bebas menggunakan kata-kata kasar, kritik, kemarahan, bahkan ancaman (Suler, 2004).

Menurut (Suler, 2004) terdapat enam faktor yang mempengaruhi munculnya fenomena online disinhibition effect dalam diri individu. Berikut penjelasan secara detil:

a. Dissociative Anonymity

Anonim membuat seseorang merasa terlindungi, karena tidak ada satu orang pun yang mengetahui siapa individu sebenarnya. Namun, anonimitas berdampak pada kerentanan individu dalam mebuka diri dan menjadi antisosial.

b. Invisibility

Komunikasi yang dilakukan dalam dunia vitual kebayakan hadir dalam bentuk teks atau emoticon, sehingga kadang tidak ada kekhawatiran akan nada dan bahasa tubuh saat berkomunikasi.

c. Asynchronicity

Asynchronicit memungkinkan individu untuk berhati-hati dalam menyampaikan apa yang ingin dikatakan sebelum dipublikasikan.

d. Solipsistic Introjection

Tanpa tatap muka, orang lain dipaksa membayangkan karakter individu berdasarkan pesan dan pesona yang dihadirkan dalam dunia virtual.

e. Dissociative Imagination

Munculnya fenomena manipulasi diri dengan mencuri identitas orang lain, menunjukkan bahwa individu melihat dunia virtual sebagai tempat bermain di mana aturan seharihari pada dunia offline tidak berlaku.

f. Minimization of Authority

Internet memberikan kedudukan yang sama bagi setiap individu, yang memungkinkan penggunanya lebih bebas dan menganggap orang lain sebagai temannya bukan sebagai suatu otoritas.

\section{METODOLOGI}

Untuk menggambarkan sudut pandang sebagai penggemar K-Pop yang memanfaatkan media sosial, penulis menggunakan pendekatan kualitatif. Pendekatan kualitatif digunakan untuk menjabarkan kejadian sosial secara deskriptif dan spesifik, agar pembaca memahami hal-hal yang terjadi di luar kejadian yang bersifat umum (Denzin dan Lincoln, 2008).

Etnografi digital merupakan teknik penelitian untuk mengkaji budaya dan komunitas online sebagai bentuk konsekuensi dari hadirnya media digital (Pink, dkk., 2016). Dalam penelitian ini etnografi digital dilakukan untuk melihat konsep manajemen impresi penggemar K-Pop dalam memanfaatkan lebih dari satu akun berbeda di media sosial Instagram.

Teknik pengumpulan informan yang digunakan dalam penelitian ini menggunakan teknik purposive sampling. Rentang usia penggermar K-Pop di Indonesia tertinggi ada pada kelompok remaja dan dewasa awal (12 - 20 tahun) (Nurani, 2017). Oleh karena itu, informan dalam penelitian ini adalah mahasiswa semester pertama pada suatu universitas di Jakarta yang merupakan penggemar K-Pop dan memiliki lebih dari satu akun Instagram. Penulis memilih 4 (empat) orang informan yang dianggap telah memenuhi kriteria pemilihan 
informan dalam penelitian etnografi digital. Informan selanjutnya dituliskan dengan inisial A, I, T, dan D.

Data primer dikumpulkan melalui observasi dan wawancara. Observasi dilakukan dengan mengamati post dari akun-akun Instagram yang dimiliki keempat informan. Selanjutnya data primer didapatkan dari wawancara dalam bentuk semi struktur dengan keempat informan. Sementara untuk data sekunder didapatkan dengan cara studi literatur pada buku dan penelitian terdahulu yang terkait.

Untuk melihat keabsahan data dilakukan triangulasi pada sumber dan teknik penelitian. Triangulasi sumber dilakukan dengan mencocokan data antar informan. Sementara triangulasi teknik penelitian dilakukan dengan membandingkan hasil wawancara dan observasi.

\section{HASIL DAN PEMBAHASAN}

Tipe Penggemar K-Pop

Menurut Samra dan Wos (2015) tipe penggemar terbagi menjadi tiga, yaitu temporary fan, devoted fan, dan fanatical fan. Temuan dari hasil wawancara menunjukkan bahwa seluruh informan termasuk dalam tipe devoted fan. Informan sebagai devoted fan dapat dilihat dalam bentuk kegiatan partisipasinya dalam fandom, seperti membeli album dan merchandise; streaming music video atau penampilan idola; mengikuti, menyukai dan mengomentari idola di SNS-nya; serta menyukai dan mengomentari berita idola di forum atau fanbase K-Pop.

Di lain sisi, seluruh informan memberikan tanggapan yang negatif mengenai kemungkinan mereka menjadi fanatical fan. Menurut mereka perbedaan buaya anatara Indonesia dan Korea Selatan memberikan gambaran berbeda dalam menjalani kehidupan sebagai seorang penggemar K-Pop dan meminimalisir kesempatan menjadi seorang sesaeng fan (sebutan penggemar fanatik dalam istilah K-Pop). Budaya Indonesia yang menjunjung tata krama mendorong penggemar untuk lebih menghargai batasan antara idola dengan penggemar. Berikut pendapat $\mathrm{T}$, sebagai gambaran devoted fan dan pendapatnya tetang fanatical fan.

"Mereka mengisnpirasiku, sehingga rasanya tepat dan pantas untuk dipresiasi balik. Bentuk apresiasiku ya sebatas kemampuanku dan dompetku. Aku voting, beli, dan streaming pas keluar album baru... Kegiatan ini aku nggak mau dibilang fanatik sih, karena aku juga mikirin apa kata orang gitu terlalu fanatik. Aku masih mikirin kehidupan normalku dan menghargai privasi mereka, karena idol juga manusia". (T, wawancara, 20 Januari 2020)

\section{Bentuk Latar Depan dan Latar Belakang Penggemar K-Pop}

Menurut Goffman (Alim, 2014), front region atau latar depan merupakan tempat bagi individu menunjukkan karakter diri yang ideal pada setiap rutinitasnya. Individu melakukan upaya untuk menumbuhkan suatu kesan dengan cara menata perilakunya dihadapan orang lain, agar dapat dipandang sebagai identitas dirinya sesuai dengan kenginannya.

Temuan dari hasil observasi dan wawancara, bahwa informan menjadikan rinsta (akun asli) sebagai latar depan (front region) dirinya di Instagram. Hasil temuan menunjukkan bahwa latar depan yang dibentuk informan pada rinsta adalah sebagai berikut:

a. Profil berisi foto diri; nama akun yang diambil dari nama lengkap atau nama panggilan; tentang diri berisi quote singkat dalam bahasa Inggris atau hanya sekedar icon. 
b. Lebih banyak mengikuti orang-orang yang dikenalnya secara umum, tetapi masih mengikuti beberapa akun resmi idolanya meski tidak sebanyak finsta.

c. Unggahan berisi video, foto, dan instastory tentang kegiatan bersama kelompok bermain dalam lingkungan kuliah atau bagian dari perjalanan wisata. Jumlah unggahan pada akun rinsta tidak banyak dibandingkan finsta. Diatur susunannya dan dibentuk sedemikian rupa dengan memanfaatkan filter Instagram.

d. Isi dari caption berisi quote singkat dalam bahasa Inggris atau hanya sekedar icon.

e. Penggunaan tagar (hastag) terkait dengan kegiatan kampus atau sama sekali tidak digunakan.

Informan tidak berusaha menutupi bahwa mereka adalah penggemar K-Pop, tetapi sangat mengurangi keinginan untuk menunjukkan obsesinya terhadap idola.

"Di akun asli masih follow akun-akun resmi oppa sama fanbase, biar update aja. Setelah tau pindah ke akun satu lagi, untuk like dan komen. Soalnya kalo like dan komen di Instagram asli, bisa nyampah di-explore yang follow aku". (D, wawancara, 20 Januari 2020)

Alasan rinsta menjadi latar depan mereka adalah karena akun tersebut diperbolehkan untuk dilihat pengguna lain secara luas; dapat diikuti (following) dan pengikutnya (followers) terdiri dari orang-orang yang disegani (orang tua dan dosen); serta menghormati perbedaan kegemaran dengan pengikut lain. Sementara latar belakang (back region) adalah tempat bagi para aktor (individu) meninggalkan perannya yang dimainkan di atas panggung, dan kembali menjadi dirinya sendiri (Mclane, 2012). Alasan finsta dapat dikatakan sebagai latar belakang penggemar K-Pop karena:

a. Akun yang diikuti (followers) dan pengikuti (following) finsta merupakan teman dekat atau orang-orang yang memiliki hobi yang sama, yaitu penggemar K-Pop.

b. Akun finsta diprivasi, di mana hanya memberikan kesempatan bagi orang-orang yang diinginkan untuk dapat mengetahui kegiatan pengguna.

c. Nama yang asing dan privasi akun memberikan kesempatan bagi informan untuk menunjukkan pendapatnya dan obsesinya lebih bebas tanpa harus tekanan.

Hal utama yang menjadi perhatian informan dalam menggunakan finsta sebagai latar belakang untuk menyembunyikan dirinya sebagai seorang penggemar K-Pop adalah pandangan orang sekitarnya yang belum menerima budaya tersebut.

"Karena di real life, K-Pop industri masih dipandang sebelah mata, kayak itu suatu hal yang alay. But actually, K-pop isn't like that. Banyak yang dapat diambil, ya biarpun ada beberapa hal negatifnya". (I, wawancara, 20 Januari 2020)

Bentuk finsta sebagai latar belakang penggemar K-Pop yang ditunjukkan dari hasil temua adalah sebagai berikut:

a. Akun diprivasi.

b. Profil berisi foto idola K-Pop atau wajah yang ditutupi sedemikian rupa; nama akun yang aneh; tentang diri menjelaskan bahwa akun sampingan, spam, atau berisi kata-kata random. 
c. Jumlah diikuti (following) lebih banyak dari pada pengikut (followers). Informan banyak mengikuti akun resmi idolanya, fanbase, dan portal berita K-Pop. Hanya menerima permintaan pertemanan dari teman dekat atau sesama pencinta K-Pop.

d. Unggahan berisi video, foto, dan instastory berisi foto pribadi yang menurut mereka memalukan untuk dilihat orang umum dan obsesi mereka terhadap idola K-Pop, seperti foto wajah, penampilan, pertunjukkan, meme dari idola K-Pop.

e. Isi dari caption finsta lebih panjang dari rinsta karena informan secara bebas mengungkapkan curahan hatinya baik terkait masalah pribadi atau sebagai seorang penggemar K-Pop. Informan lebih leluasa dan berani mengungkapkan kata-kaat kasar, amarah, atau sikap lainnya yang dipandang negative oleh masyarakat umum.

f. Penggunaan tagar (hastag) terkait dengan topik-topik yang berhubungan dengan dunia $\mathrm{K}$-Pop, seperti nama idola, grup, dan agensi entertaimen yang menaungi.

Strategi Manajemen Impresi Penggemar K-Pop

Manajemen impresi adalah terdiri dari perilaku menciptakan, mengendalikan, serta menata atau menjaga citra diri (self image) individu untuk mempengaruhi cara pandang orang lain kepada dirinya (Schlenker, 1980, dalam Alim, 2014). Manajemen impresi di media digital dilakukan dengan pengaturan dan pemanfaatan fitur-fitur di dalamnya (Cunliffe dan Corrigan, 2013).

Temuan dari hasil observasi dan wawancara menunjukkan bahwa manajemen impresi lebih banyak dilakukan pada rinsta sebagai latar depan informan untuk memanipulasi dirinya sebagai penggemar K-Pop. Hal ini terlihat dari:

a. Pada profil, informan melakukan prose edit dengan filter pada foto profilnya. Informan memilh menggunakan nama lengkap atau panggilan sebagai nama akunnya. Informasi tentang diri berisi quote dengan bahasa Inggris untuk menunjukkan kemampuan yang dimilkinya.

b. Informan dengan hati-hati menyukai dan mengomentari akun Instagram lain karena setiap kegiatn terbaca dan terlaporkan pada fitur Activity. Meski masih mengikuti akun remi idola atau fanbase K-Pop, informan sangat membatasi kegiatan like dan komentar pada akun-akun tersebut, serta hanya memilih untuk sekedar mengetahui.

c. Unggahan berisi video, foto, dan instastory hanya menampilkan kegiatan-kegiatan yang dianggap positif oleh masyarakat umum, seperti kegiatan kampus dan traveling. Unggahan pun diatur sedemekian rupa dengan memanfaatkan fitur editing pada Instagram.

d. Isi dari caption sangat diperhatikan, biasanya meyisipkan aksi unjuk diri dengan quote positif atau kalimat berbahasa asing.

e. Penggunaan tagar (hastag) jarang dilakukan, atau hanya mucul ketika terlibat dalam suatu kegiatan kampus dan acara tertentu.

Berkaitan dengan strategi manajemen impresi yang dikemukakan Jones dan Pittman (1982, dalam Mclane, 2012), penulis melihat bahwa strategi yang sesuai dengan temuan di atas yaitu:

a. Ingratiation merupakan strategi yang dilakukan dengan membuat karakteristik yang menonjol. Dalam tulisan ini, informan menujukkan karakteristiknya dengan melakukan proses editing pada profil dan unggahannya. 
b. Self-promotion adalah strategi yang dilakukan dengan menujukkan kompetensi yang dimiliki. Kompetensi diri dapat dimunculkan melalui kualitas unggahan dan isi caption seperti penggunanan bahasa asing.

\section{Bentuk Online Disinhibition Effect dari Penggemar K-Pop}

Online disinhibition effect adalah hilangnya atau diabaikannya aturan-aturan sosial dan hambatan dalam interaksi yang dilakukan pada dunia internet (Suler, 2004). Suler membagi bentuk online disinhibition effect menjadi dua, yaitu toxic disinhibition dan benign disinhibition.

Online disinhibition effect dianalisis penulis pada finsta yang lebih menunjukkan latar belakang informan sebagai penggermar K-Pop. Pada akun finsta, informan lebih berani menunjukkan dirinya yang sebenarnya. Mereka bebas mengunggah foto dengan berbagai gaya dan mengungkapkan perasaaan atau pemikirannya tanpa merasa adanya tekanan dari followers-nya.

Kegiatan informan pada finsta mereka cenderung menunjukkan bentuk toxic disinhibition. Toxic disinhibition adalah kondisi di mana seseorang lebih bebas menggunakan kata-kata kasar, kritik, kemarahan, bahkan ancaman (Suler, 2004). Memanfaatkan akun finsta, informan secara terang-terangan meluapkan apa yang dirasakannya dan dipikirkannya tanpa adanya tekanan dan tuntutan. Mereka menyukai apa yang benar-benar mereka sukai, mengomentari postingan yang mereka ingin komentari, dan mengunggah apa yang mereka obsesikan. Penggemar K-Pop tidak terlepas dari hate speech karena mereka dapat menjadi anti-fan pada idola yang mereka tidak sukai.

"Aku sering menemukan dan bahkan aku sendiri kadang juga begitu, kami menunjukkan kagum kami ke idola kami nggak hanya dengan kata-kata bagus tetapi juga kata-kata kasar bahasa Inggris yang seharusnya nggak dipake. Kita juga suka fan war dan pada akhirnya kita saling tukeran hate comment antar fandom". (A, wawancara, 20 Januari 2020)

\section{Faktor Online Disinhibition Effect Dalam Diri Penggemar K-Pop}

Penulis melihat dari hasil temuan ditunjukan beberapa faktor yang muncul dalam kegiatan penggemar K-Pop dalam finsta yang dimilikinya, yaitu:

\section{a. Dissociative Anonymity}

Dissociative Anonymity terjadi ketika individu menganggap semua yang terjadi di dunia virtual adalah anonim (Suler, 2004). Anonimitas ini membuat individu merasa terlindungi dan tidak ada orang lain yang tahu. Informan menggunakan nama-nama yang unik, aneh dan random pada akun finsta serta tidak menghubungkannya dengan SNS lain dan sulit dilacak oleh orang lain. Fitur privasi dalam Instagram pun dimanfaatkan untuk menyembunyikan diri dengan mengatur siapa saja orang yang ingin dijadikan teman. Merasa terlindungi karena anonim, informan secara nyaman dan leluasa mengungkapkan apa yang ingin diungkapkan dan diunggah, tanpa harus takut orang lain mengetahui siapa mereka sebenarnya.

\section{b. Invisibility}

Invisibility adalah faktor yang muncul karena dalam dunia vitual, kebayakan hadir dalam bentuk teks atau emoticon (Suler, 2004). Internet membantu individu untuk tidak terlihat secara fisik, sehingga kadang tidak ada kekhawatiran akan nada dan bahasa tubuh saat berkomunikasi. Faktor ini memunculkan sikap informan yang bebas menyukai dan 
berkomentar pada postingan akun resmi idola, fanbase, dan portal berita K-Pop. I, seorang penggemar menjelaskan gambaran komunikasi di akun SNS khusus K-Pop:

"Ketika meninggalkan komentar di fanbase atau portal berita K-Pop, kami cukup sering berbeda pendapat dengan pengguna lain, dan mereka akan menyerang akun kita apabila tidak diprivate". (I, wawancara, 20 Januari 2020)

\section{KESIMPULAN}

Hasil analisis yang didapatkan dari temuan dan pembahasan yang keterkaitannya terhadap teori, maka dapat disimpulkan bahwa penggemar K-Pop mencoba memanipulasi diri dengan melakukan manajemen impresi melalui akun asli (rinsta) di SNS (Instagram). Di lain sisi diri yang sebenarnya disembunyikan pada akun SNS palsu (finsta). Fenomena ini banyak muncul dengan kebijakan SNS yang memudahkan pengguna untuk membuat banyak akun, mengunakan username yang beragam, dan fitur privasi akun.

Hasil dari fenomena ini memunculkan keuntungan dan kerugian. Keuntungannya, pengguna dapat memisahkan kepentingannya, yaitu mendapatkan citra diri sesuai keinginannya di rinsta dan memuaskan obsesinya di finsta. Dampaknya, merasakan tersembunyinya diri yang nyata, membuat pengguna tanpa pikir panjang mengungkapkan apa yang ada dibenaknya tanpa memeikirkan perspektif pengguna lainnya.

Tulisan ini dilakukan pada penggemar K-Pop pada usia remaja dan dewasa awal. Hasil analisis mungkin akan berbeda dan memberikan pengetahuan tambahan terkait studi ini, jika dilakukan pada kelas umur yang terbilang dewasa. Analisis juga dapat diukur secara kualitatif untuk melihat seberapa besar faktor berpengaruh terhadap pemanfaatan rinsta dan finsta. Dengan perkembangan teknologi komunikasi, termasuk SNS yang cepat berubah akan lebih banyak potensi pengkajian yang dapat dilakukan terkait fenomena ini.

\section{DAFTAR PUSTAKA}

Alim, C. A. (2014). Impression Management Agnes Monica Melalui Akun Instagram (@agnezmo). Jurnal E-Komunikasi, 2(3), 1-10. Diambil dari https://www.neliti.com/id/publications/79686/impression-management-agnesmonica-melalui-akun-instagram-agnezmo

Ang, C.-S., \& Chan, N.-N. (2016). Adolescents' Views On Celebrity Worship: A Qualitative Study. Current Psychology, 37(1), 139-148.

Cunliffe, A. L., \& Corrigan, L. T. (2013). Dramaturgy in the internet era. Qualitative Research in Organizations and Management: An International Journal, 8(3), 308-325. https://doi.org/10.1108/QROM-05-2012-1063

Dean, J. (2017). Politicising fandom. British Journal of Politics and International Relations, 19(2), 408-424. https://doi.org/10.1177/1369148117701754

Denzin, N. K., \& Lincoln, Y. S. (2008). Introduction: The Discipline and Practice of Qualitative Research. In Handbook of Qualitative Research. In N. K. Denzin \& Y. S. Lincoln (Ed.), The Sage Handbook of Qualitative Research (Fifth, hal. 1-29). London: SAGE Publications Inc.

Dewar, S., Islam, S., Resor, E., \& Salehi, N. (2019). Finsta: Creating "fake" spaces for authentic performance. Conference on Human Factors in Computing Systems - Proceedings. https://doi.org/10.1145/3290607.3313033 
Fleming, K. L. (2007). Participatory fandom in American culture : A qualitative case study of DragonCon attendees. University of South Florida. Diambil dari http://scholarcommons.usf.edu/etd/707

Hagen, W. R. (2010). Fandom: Participatory music behavior in the age of postmodern media. University of Colorado. Diambil dari http://nc2sy9rn9h.search.serialssolutions.com/?SS_Source=3\&genre=article\&sid=ProQ :\&atitle=Fandom: Participatory music behavior in the age of postmodern media\&title=ProQuest Dissertations and Theses\&issn=\&date=2010-01$01 \&$ volume $=1 \&$ issue $=\&$ spage $=1 \& S S_{-}$docid $=20$

Hidayati, L. (2017). OKEZONE WEEK-END: Drama Korea, Pintu Masuk K-Pop ke Indonesia. Diambil 19 Januari 2020, dari https://celebrity.okezone.com/read/2017/09/22/205/1781162/okezone-week-enddrama-korea-pintu-masuk-k-pop-ke-indonesia

Hindarto, T. (2017). Manipulasi Diri dan Pelecehan Dunia Siber. Diambil 19 Januari 2020, dari https://www.qureta.com/post/manipulasi-diri-dan-pelecehan-dunia-siber

Hu, Y., Manikonda, L., \& Kambhampati, S. (2014). What we instagram: A first analysis of instagram photo content and user types. Proceedings of the 8th International Conference on Weblogs and Social Media, ICWSM 2014, 595-598.

Hutchinson, A. (2019). Twitter Adds New Account Switching Option on its Web Version, Reveals New Mac App. Diambil 10 Maret 2020, dari https://www.socialmediatoday.com/news/twitter-adds-new-account-switchingoption-on-its-web-version-reveals-new-m/556091/

Kenzy, Y. M. N., \& Sugandi, M. S. (2018). Presentasi Diri Grup K-Pop Cover Dance ( Studi Dramaturgi Pada Grup K-Pop Cover Dance Sinister ). Jurnal Ilmu Komunikasi dan Bisnis, 3(April), 104-111.

Korea.net. (2019). Hallyu (Korean Wave). Diambil dari http://www.korea.net/AboutKorea/Culture-and-the-Arts/Hallyu

Laughey, D. (2010). Media Studies: Theories And Approaches. Harpenden: Oldcastle Books.

Lin, K. Y., \& Lu, H. P. (2011). Why people use social networking sites: An empirical study integrating network externalities and motivation theory. Computers in Human Behavior, 27(3), 1152-1161. https://doi.org/10.1016/j.chb.2010.12.009

Liu, Y., \& Ying, X. (2012). A Review of Social Network Sites : Definition, Experience and Applications. In The Conference on Web Based Business Management (hal. 749-752). Chengdu: Scientific Research. Diambil dari http://www.scirp.org

Mahendra, B. (2017). Eksistensi Sosial Remaja Dalam Instagram (Sebuah Perspektif Komunikasi). Jurnal Visi Komunikasi, 16(1), 151-160. https://doi.org/10.22441/jvk.v16i1.1649

Mclane, T. A. (2012). From the Top : Impression Management Strategies and Organizational Identity in Executive-Authored Weblogs. University of Central Florida.

Nurani, N. (2017). Fanatisme Fans K-Pop: Candu dan Bumbu Remaja. Diambil 20 Januari 2020, dari https://kumparan.com/kumparank-pop/fanatisme-fans-k-pop-candu-dan-bumburemaja 
Orlando, J. (2018). How teens use fake Instagram accounts to relieve the pressure of perfection. Diambil 19 Januari 2020, dari https://theconversation.com/how-teens-usefake-instagram-accounts-to-relieve-the-pressure-of-perfection-92105

Pertiwi, W. K. (2019). Sebanyak Inikah Jumlah Pengguna Instagram di Indonesia? Diambil 19 Januari 2020, dari https://tekno.kompas.com/read/2019/12/23/14020057/sebanyakinikah-jumlah-pengguna-instagram-di-indonesia.

Pink, S., Horst, H., Postill, J., Hjorth, L., Lewis, T., \& Tacchi, J. (2016). Digital Ethnography: Principles \& Practice. SAGE Publications Ltd. London: SAGE Publications Ltd.

Rayner, P., Wall, P., \& Kruger, S. (2004). Media Studies: The Essential Resource. The Routledge Companion to Literature and Science. New York: Routledge. https://doi.org/10.4324/9780203848739.ch30

Rick, O., Fan, M., Keeler, J., \& Pfeiffer, M. (2019). Rick and Morty and Toxic Fandom: Factors Contributing to Toxic Communication in the Online Rick and Morty Fan Community. Regent University.

Samra, B., \& Wos, A. (2015). Consumer in Sports: Fan typology analysis. Journal of Intercultural Management, 6(4-1), 263-288. https://doi.org/10.2478/joim-2014-0050

Satriawan, N., Hardjono, \& Karyanta, N. A. (2016). Hubungan antara konsep diri dengan toxic disinhibition online effect pada siswa SMK N 8 Surakarta. Wacana Psikologi, 8(2), 1-12. Diambil

dari http://jurnalwacana.psikologi.fk.uns.ac.id/index.php/wacana/article/view/99/99

Suler, J. (2004). The online disinhibition effect. Cyberpsychology and Behavior, 7(3), 321-326. https://doi.org/10.1089/1094931041291295

Tartila, P. L. (2013). Fanatisme fans kpop dalam blog netizenbuzz. Commonline, 2(3), 190205. Diambil dari http://journal.unair.ac.id/download-fullpaperscomm0920a22386full.pdf 